\title{
A Citrus bergamia Extract Decreases Adipogenesis and Increases Lipolysis by Modulating PPAR Levels in Mesenchymal Stem Cells from Human Adipose Tissue
}

\author{
Debora Lo Furno, ${ }^{1}$ Adriana Carol Eleonora Graziano, ${ }^{1}$ Rosanna Avola, ${ }^{1}$ Rosario Giuffrida, \\ Vincenzo Perciavalle, ${ }^{1}$ Francesco Bonina, ${ }^{2}$ Giuliana Mannino, ${ }^{1}$ and Venera Cardile ${ }^{1}$ \\ ${ }^{1}$ Department of Biomedical and Biotechnological Sciences, Section of Physiology, University of Catania, \\ Via S. Sofia 65, 95125 Catania, Italy \\ ${ }^{2}$ Department of Drug Sciences, University of Catania, Viale A. Doria 6, 95125 Catania, Italy \\ Correspondence should be addressed to Venera Cardile; cardile@unict.it
}

Received 22 January 2016; Accepted 25 May 2016

Academic Editor: Daniele Piomelli

Copyright (C) 2016 Debora Lo Furno et al. This is an open access article distributed under the Creative Commons Attribution License, which permits unrestricted use, distribution, and reproduction in any medium, provided the original work is properly cited.

\begin{abstract}
The aim of this research was to assess the impact of a well-characterized extract from Citrus bergamia juice on adipogenesis and/or lipolysis using mesenchymal stem cells from human adipose tissue as a cell model. To evaluate the effects on adipogenesis, some cell cultures were treated with adipogenic medium plus 10 or $100 \mu \mathrm{g} / \mathrm{mL}$ of extract. To determine the properties on lipolysis, additional mesenchymal stem cells were cultured with adipogenic medium for 14 days and after this time added with Citrus bergamia for further 14 days. To verify adipogenic differentiation, oil red $\mathrm{O}$ staining at 7, 14, 21, and 28 days was performed. Moreover, the expression of peroxisome proliferator-activated receptor gamma (PPAR- $\gamma$ ), adipocytes fatty acid-binding protein (A-FABP), adipose triglyceride lipase (ATGL), hormone-sensitive lipase (HSL), monoglyceride lipase (MGL), $5^{\prime}$-adenosine monophosphateactivated protein kinase (AMPK) $\alpha 1 / 2$, and pAMPK $\alpha 1 / 2$ was evaluated by Western blot analysis and the release of glycerol by colorimetric assay. Citrus bergamia extract suppressed the accumulation of intracellular lipids in mesenchymal stem cells during adipogenic differentiation and promoted lipolysis by repressing the expression of adipogenic genes and activating lipolytic genes. Citrus bergamia extract could be a useful natural product for improving adipose mobilization in obesity-related disorders.
\end{abstract}

\section{Introduction}

Obesity, characterized by an excess accumulation of adipose tissue, has emerged as one of the leading publichealth problems in the past decades. Excess adipose tissue increases the risk for a number of metabolic disorders such as atherosclerosis, hypertension, insulin resistance, and cancer [1]. Adipocyte-derived pro- and antiinflammatory adipokines play key roles in the energy balance and homeostasis. Systemic inflammation, insulin resistance, and obesity-related metabolic disorders arise in response to increased production and secretion of proinflammatory adipokines [2]. Thus, obesity is a chronic low-grade inflammation, where a genetic predisposition, a modern sedentary life style, a reduced physical activity, and an unlimited offer of food have a major role $[3,4]$.
Actually, the most effective treatment for the weight loss is a drastic change in lifestyle, healthy diet, regular physical activity, and giving up smoking.

Several studies on cells, animals, and humans indicate dietary bioactive compounds increasing thermogenesis and energy expenditure, decreasing inflammation and oxidative stress, and supporting progress toward weight loss and/or metabolic disorders decrease $[5,6]$.

In recent years, the beneficial properties of the Citrus bergamia juice have had a growing interest and the potentiality of its health promoting substances has been the subject of research [7]. The juice of Citrus bergamia is a natural source of flavonoids, such as naringin, hesperidin, neohesperidin, and neoeriocitrin, playing a major role in human health protection $[8,9]$. Some of our findings demonstrated a marked 
antioxidant/anti-inflammatory activity of an extract from Citrus bergamia on an in vitro model of inflamed skin keratinocytes [10]. Moreover, more recently, a clinical study reported that Citrus bergamia extract supplementation has beneficial effects on plasma lipid levels also in subjects with moderate hypercholesterolemia [11].

Obesity is related to inflammation and inflammatory cytokines are highly upregulated in adipose tissue of obese subjects [12-15]. Thus, we hypothesised that the extract from Citrus bergamia juice possessing anti-inflammatory propriety could affect adipose tissue dynamics and adipocyte differentiation. Therefore, the aim of this study was to evaluate the impact of a well-characterized extract from Citrus bergamia on adipocyte differentiation using mesenchymal stem cells from human adipose tissue as a cell model.

\section{Materials and Methods}

2.1. Samples Preparation and Determination of Flavonoids. Citrus bergamia juice was obtained from peeled-off Risso et Poteau fruits collected from plantations located in Reggio Calabria (Italy). The juice was then processed as described in Graziano et al. [10]. Pure standards (neoeriocitrin, naringin, and neohesperidin) were purchased from Extrasynthese (Genay Cedex, France) and used as a comparison with labmade mixture. In any case, it is important to underline that none of the standards used alone gave results comparable to those of extract of Citrus bergamia containing a pool of flavonoid compounds.

2.2. Cultures of Mesenchymal Stem Cells. Adipose tissue was collected from 10 donors, 5 males and 5 females (from 22 to 30 years of age and mean body mass index of $29 \pm 3$ ) undergoing liposuction procedures. Lipoaspirates were obtained after the informed consent from the subjects, according to the laws of the Italian Government. The mesenchymal stem cells from lipoaspirates were obtained as reported in Lo Furno et al. [16].

2.3. Identification of Mesenchymal Stem Cells Markers. In order to detect the type of cells derived from lipoaspirates, flow cytometry was carried out as reported in Musumeci et al. [17].

2.4. Differentiation of Mesenchymal Stem Cells in Adipocytes. The ability of mesenchymal stem cells to differentiate towards the adipogenic line was examined in experiments where these were put in culture for $7,14,21$, and 28 days. Some cells, as a control, were incubated in DMEM-1g (10\% FBS, $1 \%$ penicillin/streptomycin, $1 \%$ of MSC growth supplement). Additional cells were maintained with adipogenic medium (human MesenCult MSC Basal Medium plus Adipogenic Stimulatory Supplement; cat. \#05401 and \#05403, resp.; StemCell Technologies, Milan, Italy).

2.5. Treatments with Citrus bergamia Extract. To evaluate the effects on adipogenesis, some cell cultures with or without adipogenic medium were treated with 10 or $100 \mu \mathrm{g} / \mathrm{mL}$ of characterized and lyophilized Citrus bergamia added to the medium every 2-3 days during medium changes for 28 days.
To determine the properties on lipolysis, additional cells were cultured with or without adipogenic medium for 14 days. After this time, they were added with 10 or $100 \mu \mathrm{g} / \mathrm{mL}$ of Citrus bergamia for further 14 days.

2.6. Oil Red O Staining. To verify adipogenic differentiation of cell cultures, oil red $\mathrm{O}$ staining at $7,14,21$, and 28 days was performed. Oil red $\mathrm{O}$ is a lysochrome diazo dye (fatsoluble) used for staining of neutral triglycerides and lipids on sections and cells. For this, cells in 6-well plates were gently rinsed with PBS and fixed in a 10\% formalin-PBS solution for 1 hour. After removing this solution, $125 \mu \mathrm{L}$ of $0.3 \%$ oil red O-isopropyl alcohol was added to each well and kept at room temperature for $15 \mathrm{~min}$ to stain the cells. After $15 \mathrm{~min}$, each well was washed three times, and the dye in the cells was eluted with $125 \mu \mathrm{L}$ of isopropyl alcohol. Then, $100 \mu \mathrm{L}$ of the eluate in each well was transferred to 96 -well plates, and the optical density at $\lambda=550 \mathrm{~nm}$ was measured using a microplate reader.

2.7. Determination of Adipogenic and Lipolytic Markers. The expression of peroxisome proliferator-activated receptor gamma (PPAR- $\gamma$ ), adipocytes fatty acid-binding protein (A-FABP), adipose triglyceride lipase (ATGL), hormonesensitive lipase (HSL), monoglyceride lipase (MGL), $5^{\prime}$-adenosine monophosphate-activated protein kinase $(\mathrm{AMPK}) \alpha 1 / 2$, and $\mathrm{pAMPK} \alpha 1 / 2$ was evaluated by Western blot analysis as described in Lo Furno et al. [16]. The antibodies used were anti-PPAR- $\gamma$ (H-100: sc-7196, Santa Cruz Biotechnology, Santa Cruz, CA,) (dilution 1:300), anti-A-FABP (C-15: sc-18661) (dilution 1:300), anti-ATGL (H-144: sc-67355) (dilution 1:300), anti-HSL (H-300: sc-25843) (dilution 1:200), anti-MGL (H-300: sc-134789) (dilution 1 : 200), anti-AMPK $\alpha 1 / 2$ (H300: sc-25792) (dilution 1:200), anti-p-AMPK $\alpha 1 / 2$ (Thr 172: sc-33524) (dilution $1: 300)$, and anti- $\alpha$-tubulin (T9026; Sigma-Aldrich) (1:5000 dilution). The signal intensity of primary antibody binding was analyzed quantitatively with ImageJ software and was normalized to a loading control $\alpha$-tubulin. Values were expressed as arbitrary densitometric units (ADU) corresponding (proportional) to signal intensity.

2.8. Glycerol Assay. Glycerol determination was performed by colorimetric assay kit from Cayman (item number 10010755) that measures glycerol by a coupled enzymatic reaction system. Glycerol is phosphorylated by glycerol kinase to produce glycerol-3-phosphate and adenosine- $5^{\prime}$ diphosphate. The glycerol-3-phosphate is oxidized by glycerol phosphate oxidase producing dihydroxyacetone phosphate and hydrogen peroxide $\left(\mathrm{H}_{2} \mathrm{O}_{2}\right)$. Peroxidase catalyses the redox-coupled reaction of $\mathrm{H}_{2} \mathrm{O}_{2}$ with 4-aminoantipyrine and $\mathrm{N}$-ethyl-N-(3-sulfopropyl)-m-anisidine, producing a brilliant purple product with an absorbance maximum at $\lambda=$ $540 \mathrm{~nm}$. The results were expressed as $\mu \mathrm{g} / \mathrm{L}$ glycerol (dynamic range of the kit was $0-20 \mu \mathrm{g} / \mathrm{L}$ glycerol).

2.9. Cell Viability Assay. The effect on cell viability of Citrus bergamia was evaluated with a test based on the cleavage of 3-(4,5-dimethyl-2 thiazolyl)-2,5-diphenyl-2H-tetrazolium 
TABLE 1: Mesenchymal stem cells markers identified by flow cytometric analysis.

\begin{tabular}{lc}
\hline Cell surface (cluster of differentiation) marker & \% positive cells \\
\hline CD44 & $95.5 \pm 0.3$ \\
CD90 & $88.6 \pm 0.5$ \\
CD105 & $80.2 \pm 1.6$ \\
CD14 & $8.3 \pm 6.2$ \\
CD34 & $5.5 \pm 6.3$ \\
CD45 & $9.7 \pm 6.2$ \\
\hline
\end{tabular}

bromide (MTT) by mitochondrial dehydrogenases of metabolically active cells [18]. The optical density at $\lambda=550 \mathrm{~nm}$ was measured using a microplate reader.

2.10. Statistical Analysis. All data were presented as mean \pm SD of at least three separate experiments. The statistical analysis was performed by using two-way ANOVA followed by Dunnett's post hoc test for multiple comparisons with control. All statistical analyses were performed using the statistical software package SYSTAT, version 11 (Systat Inc., Evanston IL, USA). The unpaired Student's $t$-test was used to compare two different groups. A $p$ value $<0.05$ was considered to be statistically significant.

\section{Results}

3.1. Determination of Flavonoids. The flavonoids profile of Citrus bergamia extract enriched in polyphenols was reported in Graziano et al. [10]. Briefly, the main flavonoids identified by HPLC and HPLC-MS were apigenin 6,8-di $C$-glucoside, diosmetin 6,8-di $C$-glucoside, neoeriocitrin, naringin, and neohesperidin. The total amount of flavonoids in Citrus bergamia solid extract was $25-27 \% \mathrm{w} / \mathrm{w}$. The content of flavonoids, according to HPLC analysis, was as follows: neoeriocitrin $(5.2 \pm 0.3 \%)$, naringin $(8.9 \pm 0.2 \%)$, neohesperidin $(13.1 \pm 0.3 \%)$, and other flavonoids $(5 \pm 0.8 \%)$.

3.2. Identification of Mesenchymal Stem Cells Markers. After the first passage, flow cytometry analysis demonstrated that mesenchymal stem cells did not present labeling for hematopoietic line markers (CD45, CD14, and CD34) and were positive for CD44, CD90, and CD105 (Table 1).

3.3. Effect of Citrus bergamia on Cell Viability. The results of the MTT assay (Figure 1) showed that Citrus bergamia has no effect on cell viability, because treatment with $1,10,50$, and $100 \mu \mathrm{g} / \mathrm{mL}$ for 48 hours did not reduce the ability of stem cell cultures to metabolise tetrazolium salts at any concentration.

3.4. Effect of Citrus bergamia on Adipogenesis or Lipolysis. Adipocytes were verified by the presence of intracellular vesicles containing lipid by means of staining with oil red O. In the control cells there was no staining while in the mesenchymal stem cells treated with adipogenic medium it was possible to appreciate the formation of large vacuoles containing lipids in which it was evident to be a red-orange staining (Figure 2(a)), which increased in size in a timedependent manner. The number of these cells increased

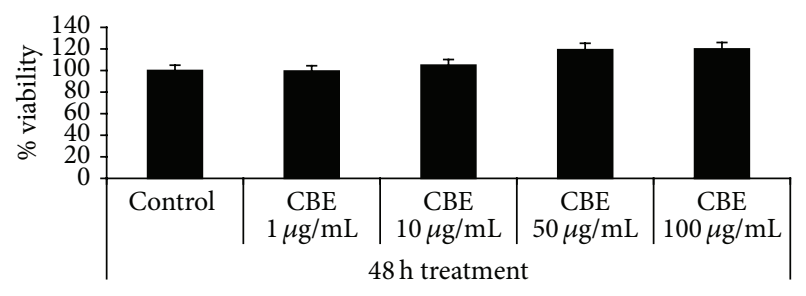

FIGURE 1: Effects of Citrus bergamia extract (CBE) on mesenchymal stem cells viability, determined using the 3-(4,5-dimethyl-2 thiazolyl)-2,5-diphenyl-2H-tetrazolium bromide (MTT) assay, after 48 hours of treatment with $1,10,50$, or $100 \mu \mathrm{g} / \mathrm{mL}$ of CBE. The values of optical density measured at $\lambda=550 \mathrm{~nm}$ are reported as percentage with respect to the optical density registered for untreated control (Control), the latter considered as $100 \%$ of cell viability. The values are mean \pm SD of three experiments performed in triplicate.

continuously up to the 28th day of culture (Figure 2(a)). More than $60 \%$ of human mesenchymal stem cells were differentiated into adipocytes within the four-week induction period. Differently, the cell cultures with adipogenic medium treated with 10 or $100 \mu \mathrm{g} / \mathrm{mL}$ of Citrus bergamia showed a decrease in the number and size of intracellular lipid vacuoles in a concentration-dependent manner (Figure 2(a)).

Compared to the differentiated adipocytes, mesenchymal stem cells cultured with adipogenic medium for 14 days and after this time added with 10 or $100 \mu \mathrm{g} / \mathrm{mL}$ of Citrus bergamia for further 14 days displayed a lower number of smaller size vacuoles (Figure 3(a)). Oil red O lipid quantification confirmed that Citrus bergamia decreased lipid accumulation in a time- and concentration-dependent manner (Figures 2(b) and 3(b)).

3.5. Determination of Adipogenesis Markers. To elucidate the mechanism of the differentiation inhibitory effect of Citrus bergamia, the protein expression levels of PPAR- $\gamma$, A-FABP, and AMPK $\alpha 1 / 2$ were evaluated by Western blot analysis at $7,14,21$, and 28 days in differently treated cells. PPAR- $\gamma$ was weakly detected in undifferentiated cells, and its expression level increased in time-dependent manner during adipocyte differentiation, as compared with that in the undifferentiated cells (Figure 4). In contrast, when the cells were caused to differentiate into adipocytes in medium containing Citrus bergamia at 10 or $100 \mu \mathrm{g} / \mathrm{mL}$, the expression of PPAR- $\gamma$ was reduced. At $100 \mu \mathrm{g} / \mathrm{mL}$, the levels for PPAR- $\gamma$ were decreased to approximately $39,45,58$, and $66 \%$ at $7,14,21$, and 28 days, respectively, compared to the differentiated cells (Figure 4).

A-FABP is a cytoplasmatic protein highly expressed in adipocytes. Our results showed that, compared to mesenchymal stem cells differentiated with adipogenic medium for 28 days, incubation with Citrus bergamia decreased the total A-FABP content in a time- and concentration-dependent manner (Figure 4).

To elucidate the molecular mechanism of the suppressive effect of Citrus bergamia extract on adipogenesis, we investigated the possibility of Citrus bergamia acting as an activator of AMPK $\alpha 1 / 2$. It is known that the activation of AMPK 

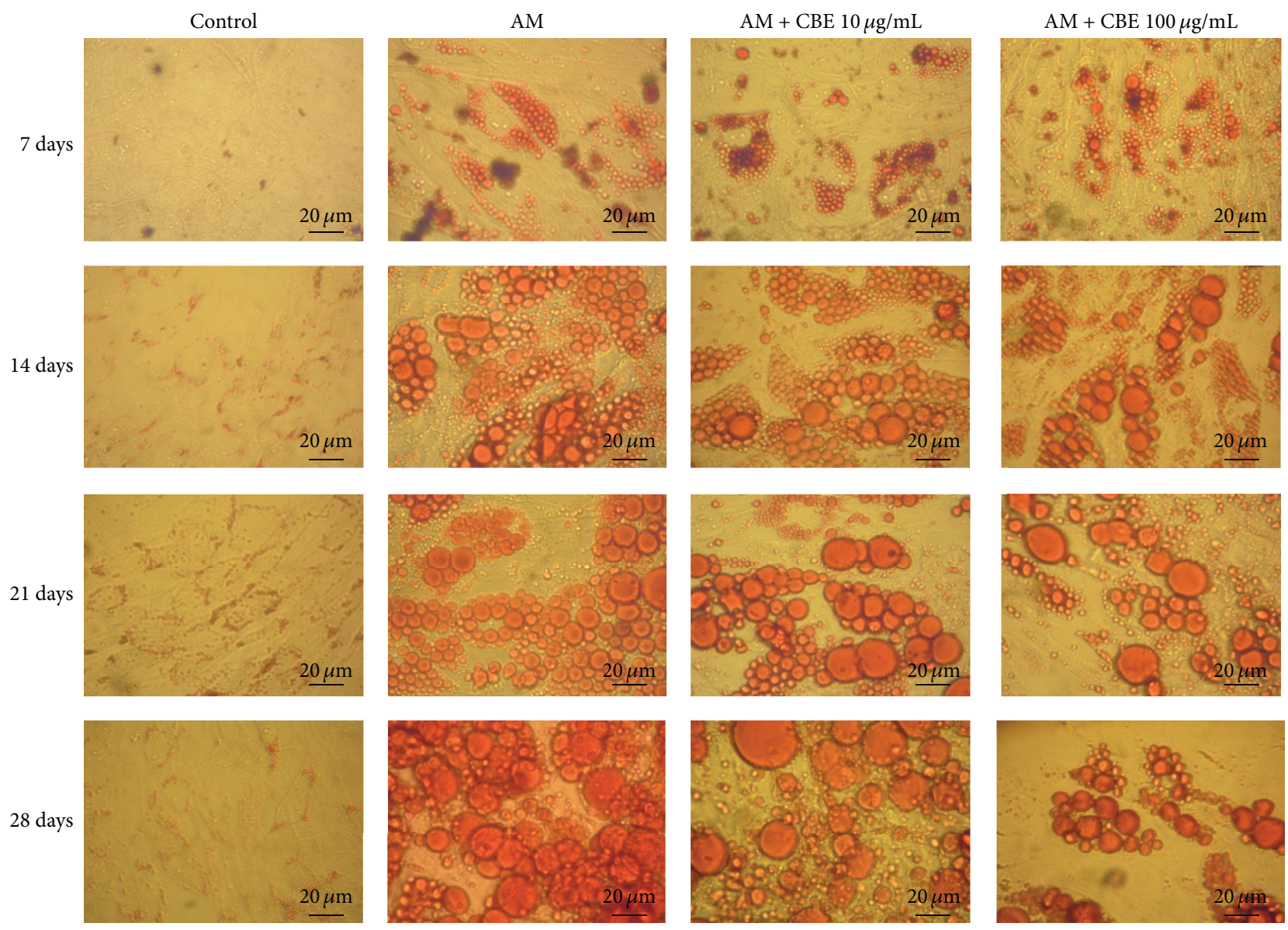

(a)

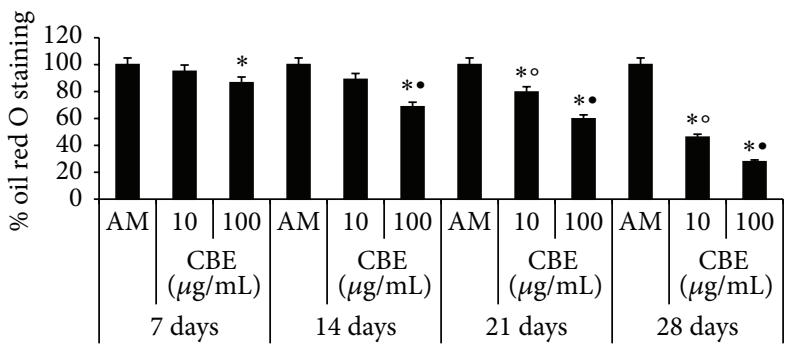

(b)

Figure 2: Effect of 10 and $100 \mu \mathrm{g} / \mathrm{mL}$ Citrus bergamia extract (CBE) on the lipid content of mesenchymal stem cells stained with oil red O during adipogenic differentiation. Cells were examined at 7, 14, 21, and 28 days from the start of differentiation. (a) A representative photograph from three independent experiments of untreated control (Control), adipogenic medium-treated cells (AM), and AM plus $10 \mathrm{or} 100 \mu \mathrm{g} / \mathrm{mL}$ CBE was shown. (b) The levels of oil red O incorporation were quantified by measuring the absorbance of isopropyl alcohol extract at $\lambda=$ $550 \mathrm{~nm}$. Data were shown relative to AM and expressed as mean \pm SD from three independent experiments. ${ }^{*} p<0.01$ versus AM (100\%) at same day; ${ }^{\circ} p<0.05$ versus $\mathrm{CBE} 10 \mu \mathrm{g} / \mathrm{mL}$ at 7 days; ${ }^{\circ} p<0.01$ versus $\mathrm{CBE} 100 \mu \mathrm{g} / \mathrm{mL}$ at 7 days.

suppresses adipogenesis [19]. AMPK $\alpha 1 / 2$ was expressed constitutively even in the absence of Citrus bergamia. Phosphorylation of AMPK $\alpha 1 / 2$ was enhanced when the cells were cultured in DMEM containing 10 or $100 \mu \mathrm{g} / \mathrm{mL}$ Citrus bergamia, although the AMPK $\alpha 1 / 2$ level in any sample was not altered by this treatment (Figure 4). Furthermore, the efficiency of phosphorylation of AMPK at 7 days was similar than that at 28 days, revealing that Citrus bergamia rapidly phosphorylated AMPK $\alpha 1 / 2$ in these cells.

3.6. Determination of Lipolysis Markers. Differentiated adipocytes from mesenchymal stem cells cultured with adipogenic medium for 14 days and after this time treated with 10 or $100 \mu \mathrm{g} / \mathrm{mL}$ of Citrus bergamia for further 14 days displayed 

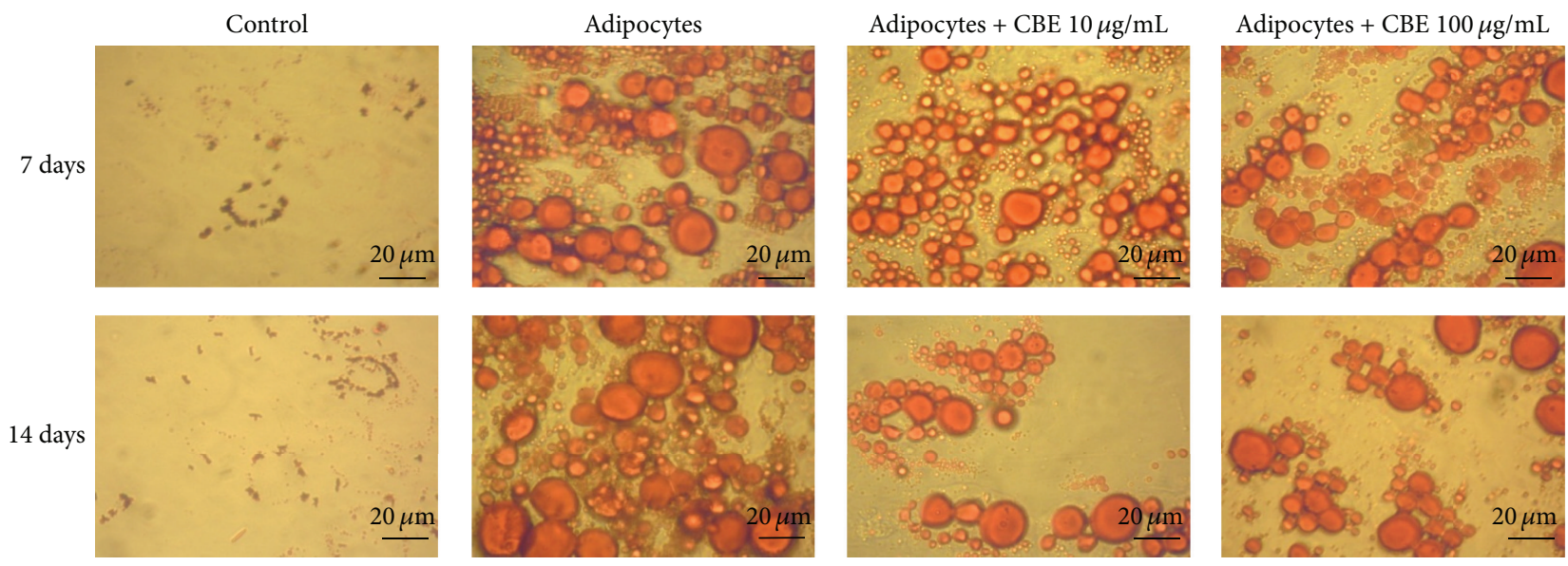

(a)

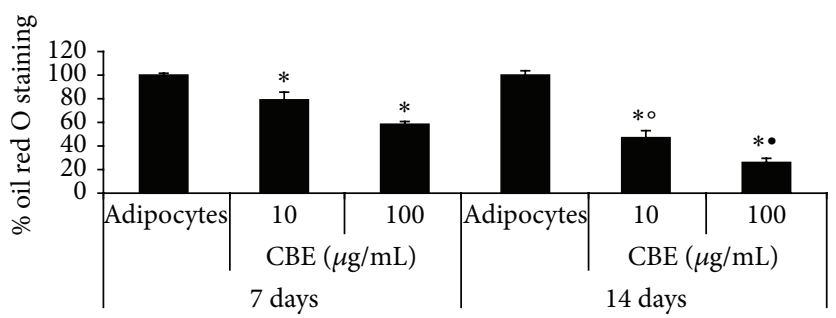

(b)

Figure 3: Effect of 10 and $100 \mu \mathrm{g} / \mathrm{mL}$ Citrus bergamia extract (CBE) on the lipid content of 14-day differentiated adipocytes stained with oil red O. (a) A representative photograph from three independent experiments of untreated mesenchymal stem cells (Control), 14-day differentiated cells (adipocytes), adipocytes with 10 or $100 \mu \mathrm{g} / \mathrm{mL}$ CBE at 7 and 14 days was shown. (b) The levels of oil red O incorporation was quantified by measuring the absorbance of isopropyl alcohol extract at $\lambda=550 \mathrm{~nm}$. Data were shown relative to 14-day differentiated adipocytes and expressed as mean \pm SD from three independent experiments. ${ }^{*} p<0.01$ versus the 14 -day differentiated adipocytes (100\%) at same day; ${ }^{\circ} p<0.01$ versus $\mathrm{CBE} 10 \mu \mathrm{g} / \mathrm{mL}$ at 7 days; ${ }^{\circ} p<0.01$ versus $\mathrm{CBE} 100 \mu \mathrm{g} / \mathrm{mL}$ at 7 days.

a concentration- and time-dependent decrease of PPAR- $\gamma$ (Figure 5).

Moreover, we examined the expression of genes involved in the lipolysis such as ATGL, HSL, and MGL and measured glycerol release from the cells treated or not with Citrus bergamia extract.

The production of ATGL, HSL, and MGL was upregulated by Citrus bergamia extract in a time- and concentrationdependent manner, as compared with that of the 14-day differentiated adipocytes (Figure 5).

Furthermore, the treatment of 14-day differentiated adipocytes with 10 or $100 \mu \mathrm{g} / \mathrm{mL}$ of Citrus bergamia extract significantly increased the content of free glycerol to $8 \pm 2$ and $19 \pm 4 \mu \mathrm{g} / \mathrm{mL}$, respectively, as compared to control cells at $3 \pm 0.5 \mu \mathrm{g} / \mathrm{mL}$ (Figure 6).

\section{Discussion}

In this study, we reveal that a Citrus bergamia extract suppressed the accumulation of intracellular lipids in mesenchymal stem cells during adipogenic differentiation and promoted lipolysis by repressing the expression of adipogenic genes and activating lipolytic genes. The Citrus bergamia-mediated suppression of adipogenesis occurred through decrease of PPAR- $\gamma$ and A-FABP and activation of
AMPK. The Citrus bergamia-mediated activation of lipolysis occurred through increase of ATGL, HSL, and MGL expression and glycerol release.

It is well known that obesity occurs because of an imbalance between energy intake and expenditure, leading to increased numbers of adipocytes (hyperplasia) and increased adipocytes size (hypertrophy) [2]. On the contrary, lipolysis is one of the most important mechanisms to reduce adipose mass, leading to the breakdown of triacylglycerol stored in adipocytes and release of free fatty acids and glycerol [3]. Accordingly, the inhibition of the differentiation and proliferation of adipocytes and/or the promotion of fat mobilization in adipocytes could be used as a strategy for the treatment and prevention of obesity.

Several natural products have been reported to be involved in the suppression of adipogenesis [19]. Among these, flavonoids are naturally occurring polyphenolic compounds present in a variety of fruits, vegetables, and seeds [19]. These products possess many biological, pharmacological, antioxidant, and antimicrobial activities [20-22].

Citrus is one of the most important fruit crops worldwide and is rich in nutrients and bioactive compounds. Citrus fruits contain not only basic nutrient compounds such as vitamins, minerals, pectins, and dietary fibers, but also ample bioactive compounds including flavonoids, 


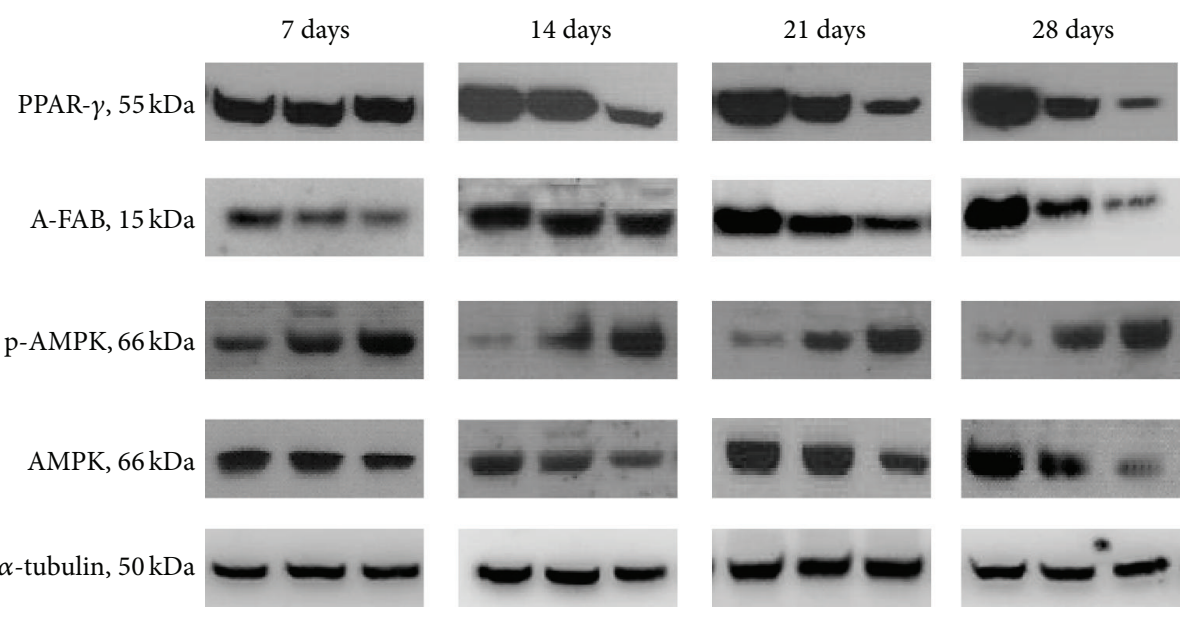

(a)
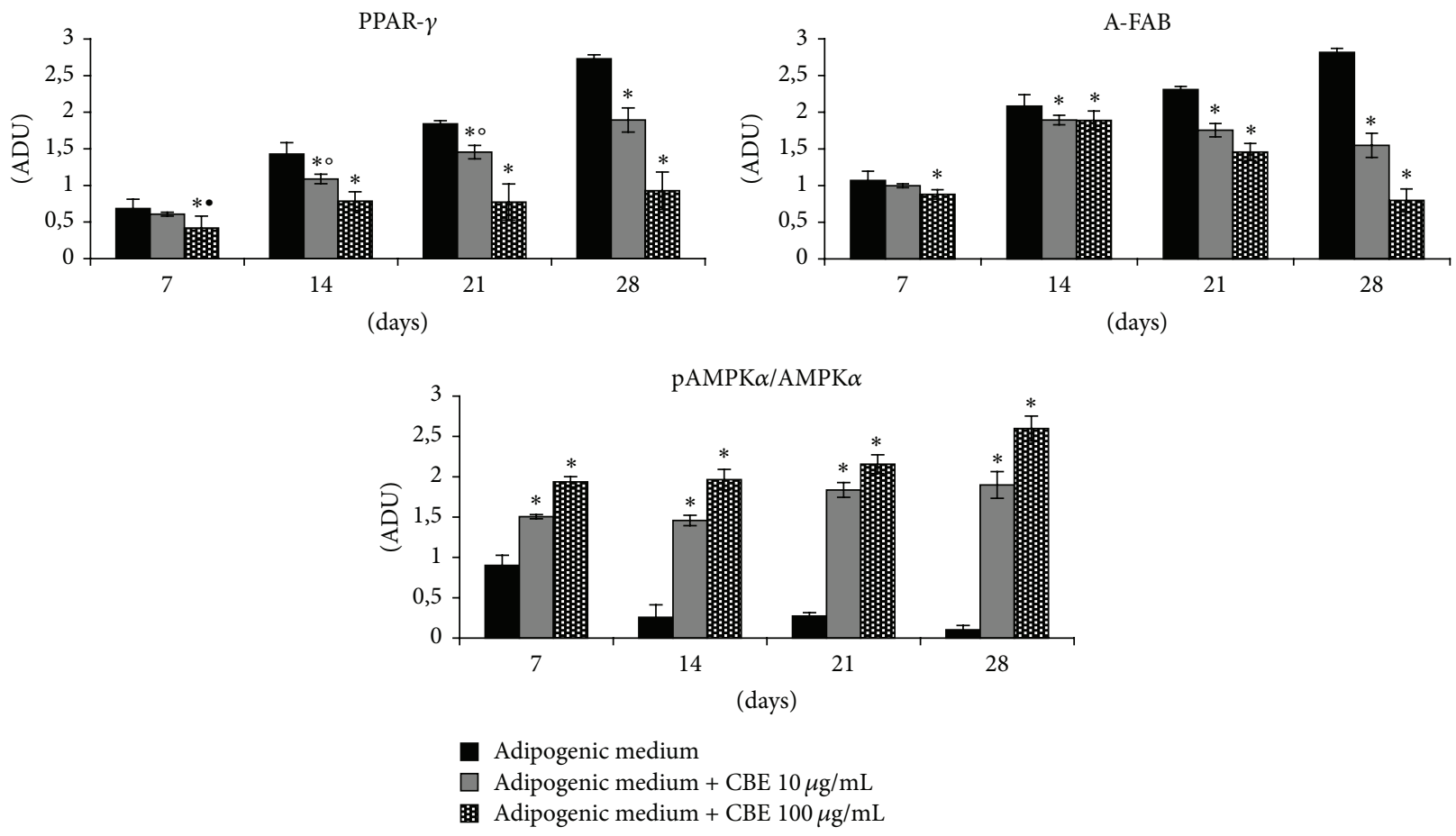

(b)

FIGURE 4: Inhibitory effects of 10 or $100 \mu \mathrm{g} / \mathrm{mL}$ Citrus bergamia extract (CBE) on adipocyte differentiation in mesenchymal stem cells induced to differentiate into adipocytes by using adipogenic medium in presence or absence of CBE. At 7, 14, 21, and 28 days, differentiated mesenchymal stem cells adipocytes were examined for PPAR- $\gamma, \mathrm{A}-\mathrm{FAB}, \mathrm{AMPK} \alpha 1 / 2$, and p-AMPK $\alpha 1 / 2$ by Western blot. The levels of proteins were expressed as arbitrary densitometric units (ADU) and the ratio p-AMPK $\alpha 1 / 2 / A M P K \alpha 1 / 2$. Data are shown relative to adipogenic-treated cells and expressed as mean \pm SD from three independent experiments. ${ }^{*} p<0.01$ versus the mesenchymal stem cells treated with adipogenic medium at same day; ${ }^{\circ} p<0.01$ versus $\mathrm{CBE} 10 \mu \mathrm{g} / \mathrm{mL}$ at 28 days; ${ }^{\circ} p<0.01$ versus $\mathrm{CBE} 100 \mu \mathrm{g} / \mathrm{mL}$ at 28 days.

carotenoids, limonoids, and coumarins. In recent years, the study on the use of citrus fruits in the prevention and treatment of obesity and its related metabolic diseases has attracted increasing attention [23-27].

Citrus bergamia, commonly named bergamot, is a fruit mainly used for its essential oil extracted from the peel in the pharmaceutical industry, in the cosmetic industry, and in food industries as aroma. On the contrary, the juice because of its bitter taste has not found a real use in the industry and it is considered a waste of the essential oil production. However, the juice is a natural source of flavonoids, especially in terms of naringin, hesperidin, neohesperidin, and neoeriocitrin [18]. In this research, we demonstrated that Citrus bergamia extract affects adipogenesis and lipolysis giving a new useful suggestion for the industry on use of bergamot juice, which otherwise would be an unusable waste product.

Adipocyte differentiation is regulated by a complex mechanism including transcriptional regulation for coordinate 


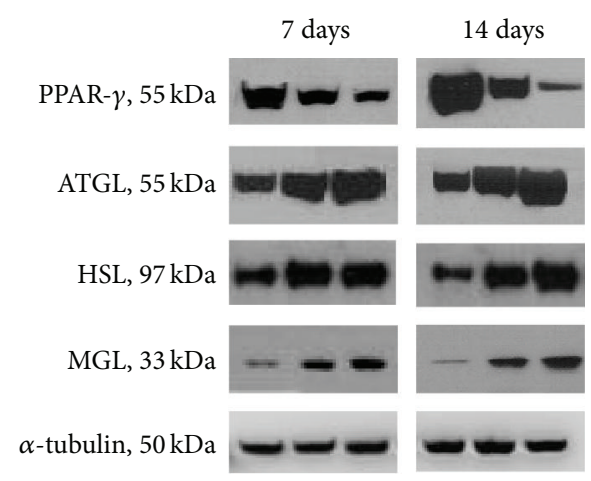

(a)
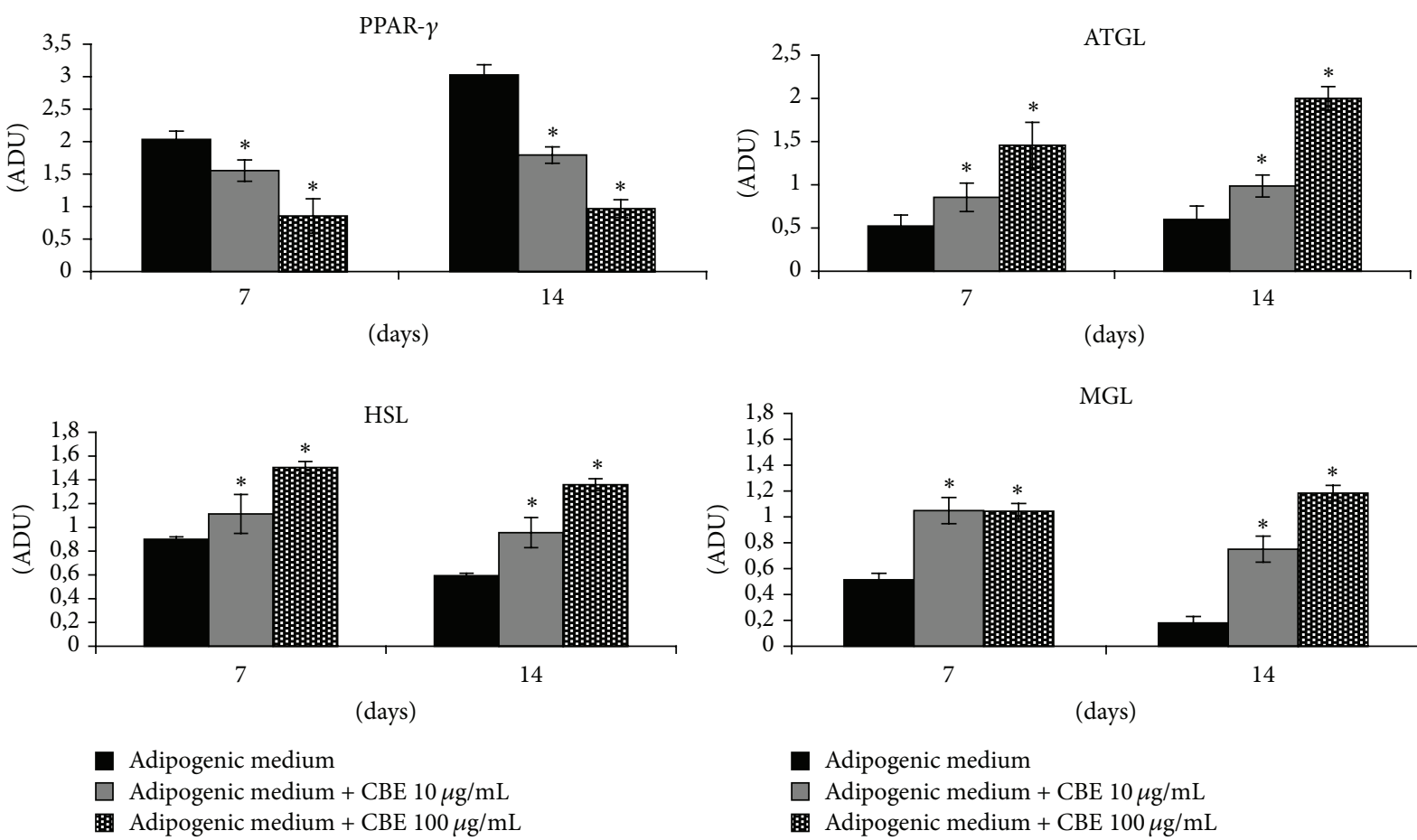

(b)

FIgURE 5: Effects of Citrus bergamia extraction on PPAR- $\gamma$, ATGL, HSL, and MGL: 14-days differentiated adipocytes were treated with 10 or $100 \mu \mathrm{g} / \mathrm{mL}$ for 7 or 14 days. The levels of proteins are expressed as arbitrary densitometric unit (ADU). Data were shown relative to 14day differentiated adipocytes (adipocytes) and expressed as mean \pm SD from three independent experiments. ${ }^{*} p<0.01$ versus the 14 -day differentiated adipocytes (100\%).

changes in the expression of adipocyte-specific genes [28]. PPAR- $\gamma$ is a key nuclear receptor transcription factor in adipogenesis and lipogenesis [29-33]. It regulates the expressions of the genes related to fatty acid oxidation, synthesis, and adipogenesis. Our results indicated that Citrus bergamia extract decreased the expression of PPAR- $\gamma$ suppressing the differentiation of the preadipocytes into adipocytes.

It is known that activated AMPK attenuates adipogenesis including the synthesis of glycerol lipids and augments fatty acid oxidation $[34,35]$. It was reported also that AMPK can be activated by flavonoids such as quercetin and epigallocatechin gallate [32], both of which suppress adipogenesis. Regarding the molecular mechanism, Thr172 residue of AMPK $\alpha$-subunits is phosphorylated by liver kinase B1 or by calcium/calmodulin-dependent protein kinase kinase- $\beta$ $[36,37]$.

Our data showed that Citrus bergamia extract enhanced the phosphorylation of AMPK in mesenchymal stem cells, indicating that it acts as an activator of AMPK. Probably, Citrus bergamia extract modulates the activity of calcium/calmodulin-dependent protein kinase kinase- $\beta$, triggers the AMPK cascade in adipocytes, and attenuates the progression of adipogenesis.

In summary, we presently show that Citrus bergamia suppressed adipogenesis through downregulation of PPAR$\gamma$ function by activating AMPK in adipocytes differentiated from mesenchymal stem cells. Thus, Citrus bergamia extract has the potential for use as an antiadipogenic agent to lower 

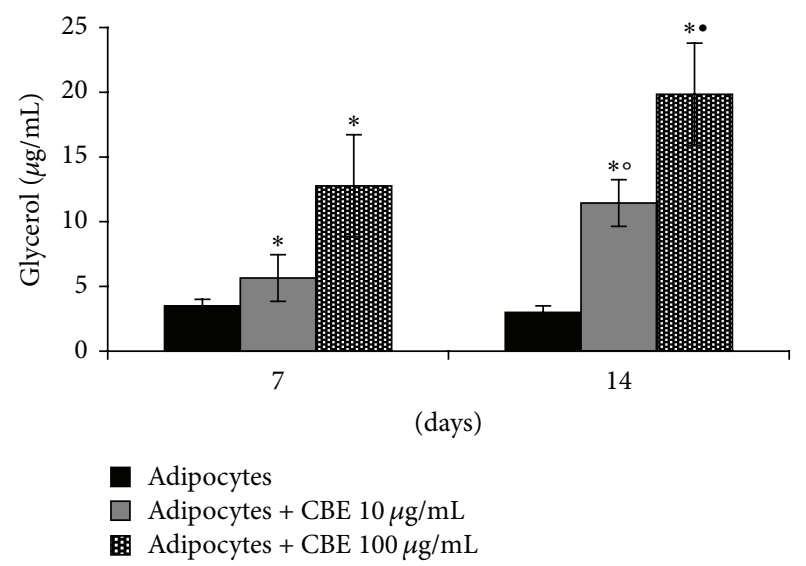

Figure 6: Stimulation of lipolysis by 10 or $100 \mu \mathrm{g} / \mathrm{mL}$ Citrus bergamia extract (CBE) in 14-day differentiated adipocytes, assessed by the amount of glycerol released into the media. Data were expressed $(\mu \mathrm{g} / \mathrm{mL})$ as mean \pm SD from a representative triplicate experiment. ${ }^{*} p<0.01$ versus the 14 -day differentiated adipocytes; ${ }^{\circ} p<0.05$ versus $\mathrm{CBE} 10 \mu \mathrm{g} / \mathrm{mL}$ at 7 days; ${ }^{\circ} p<0.01$ versus $\mathrm{CBE}$ $100 \mu \mathrm{g} / \mathrm{mL}$ at 7 days.

the content of body fat and prevent a gain in body weight. It is also necessary to underline that the 3T3-L1 cells have been used as a model in the majority of the in vitro studies published until now [38-40]. In the present research, we used mesenchymal stem cells from human adipose tissue confirming them as a good model to study the effects of polyphenols or other natural compounds on obesity.

\section{Conclusions}

In conclusion, the results of this study showed that Citrus bergamia extract, containing a good pool of compounds such as neoeriocitrin, naringin, neohesperidin, and other flavonoids, effectively reduces the level of intracellular neutral lipid by promoting triglycerides metabolism in order to diminish fat stores in adipocytes, thereby combating obesity. Additionally, Citrus bergamia extract displayed a significant inhibitory effect on adipogenesis, reducing a capacity to produce mature adipocytes from mesenchymal stem cells and regulating adipose tissue mass.

Therefore, Citrus bergamia extract could be a useful natural product for improving adipose mobilization in obesityrelated disorders.

\section{Competing Interests}

The authors declare no actual or potential conflict of interests.

\section{Authors' Contributions}

Debora Lo Furno and Adriana Carol Eleonora Graziano contributed equally to this study.

\section{Acknowledgments}

This work was supported by grant from Ricerca Finanziata Ateneo (University of Catania) Cod. 21040104.

\section{References}

[1] A. H. Mokdad, E. S. Ford, B. A. Bowman et al., "Prevalence of obesity, diabetes, and obesity-related health risk factors, 2001," Journal of the American Medical Association, vol. 289, no. 1, pp. 76-79, 2003.

[2] K. Sun, C. M. Kusminski, and P. E. Scherer, "Adipose tissue remodeling and obesity," Journal of Clinical Investigation, vol. 121, no. 6, pp. 2094-2101, 2011.

[3] H. H. M. Maes, M. C. Neale, and L. J. Eaves, "Genetic and environmental factors in relative body weight and human adiposity," Behavior Genetics, vol. 27, no. 4, pp. 325-351, 1997.

[4] S. O'Rahilly, "Human genetics illuminates the paths to metabolic disease," Nature, vol. 462, no. 7271, pp. 307-314, 2009.

[5] S. Wang, N. Moustaid-Moussa, L. Chen et al., "Novel insights of dietary polyphenols and obesity," Journal of Nutritional Biochemistry, vol. 25, no. 1, pp. 1-18, 2014.

[6] N. Siriwardhana, N. S. Kalupahana, M. Cekanova, M. LeMieux, B. Greer, and N. Moustaid-Moussa, "Modulation of adipose tissue inflammation by bioactive food compounds," Journal of Nutritional Biochemistry, vol. 24, no. 4, pp. 613-623, 2013.

[7] R. Pernice, G. Borriello, R. Ferracane, R. C. Borrelli, F. Cennamo, and A. Ritieni, "Bergamot: a source of natural antioxidants for functionalized fruit juices," Food Chemistry, vol. 112, no. 3, pp. 545-550, 2009.

[8] G. Mandalari, R. N. Bennett, A. R. Kirby et al., "Enzymatic hydrolysis of flavonoids and pectic oligosaccharides from bergamot (Citrus bergamia Risso) peel," Journal of Agricultural and Food Chemistry, vol. 54, no. 21, pp. 8307-8313, 2006.

[9] L. Di Donna, G. De Luca, F. Mazzotti et al., "Statin-like principles of bergamot fruit (Citrus bergamia): isolation of 3hydroxymethylglutaryl flavonoid glycosides," Journal of Natural Products, vol. 72, no. 7, pp. 1352-1354, 2009.

[10] A. C. E. Graziano, V. Cardile, L. Crascì et al., "Protective effects of an extract from Citrus bergamia against inflammatory injury in interferon-gamma and histamine exposed human keratinocytes," Life Sciences, vol. 90, no. 25-26, pp. 968-974, 2012.

[11] P. P. Toth, A. M. Patti, D. Nikolic et al., "Bergamot reduces plasma lipids, atherogenic small dense LDL, and subclinical atherosclerosis in subjects with moderate hypercholesterolemia: a 6 months prospective study," Frontiers in Pharmacology, vol. 6, article 299, 2016.

[12] D. Carling, F. V. Mayer, M. J. Sanders, and S. J. Gamblin, "AMP-activated protein kinase: nature's energy sensor," Nature Chemical Biology, vol. 7, no. 8, pp. 512-518, 2011.

[13] S. P. Poulos, M. V. Dodson, and G. J. Hausman, "Cell line models for differentiation: preadipocytes and adipocytes," Experimental Biology and Medicine, vol. 235, no. 10, pp. 1185-1193, 2010.

[14] S.-O. Kim, K. Sakchaisri, Y. Asami et al., "Illudins C2 and C3 stimulate lipolysis in 3T3-L1 adipocytes and suppress adipogenesis in 3T3-L1 preadipocytes," Journal of Natural Products, vol. 77, no. 4, pp. 744-750, 2014.

[15] C. Andersen, S. Rayalam, M. A. Della-Fera, and C. A. Baile, "Phytochemicals and adipogenesis," BioFactors, vol. 36, no. 6, pp. 415-422, 2010.

[16] D. Lo Furno, A. C. E. Graziano, S. Caggia et al., "Decrease of apoptosis markers during adipogenic differentiation of mesenchymal stem cells from human adipose tissue," Apoptosis, vol. 18, no. 5, pp. 578-588, 2013.

[17] G. Musumeci, A. Mobasheri, F. M. Trovato et al., "Biosynthesis of collagen I, II, RUNX2 and lubricin at different time points of 
chondrogenic differentiation in a 3D in vitro model of human mesenchymal stem cells derived from adipose tissue," Acta Histochemica, vol. 116, no. 8, pp. 1407-1417, 2014.

[18] T. Mosmann, "Rapid colorimetric assay for cellular growth and survival: application to proliferation and cytotoxicity assays," Journal of Immunological Methods, vol. 65, no. 1-2, pp. 55-63, 1983.

[19] G. Di Carlo, N. Mascolo, A. A. Izzo, and F. Capasso, "Flavonoids: old and new aspects of a class of natural therapeutic drugs," Life Sciences, vol. 65, no. 4, pp. 337-353, 1999.

[20] K. B. Pandey and S. I. Rizvi, "Plant polyphenols as dietary antioxidants in human health and disease," Oxidative Medicine and Cellular Longevity, vol. 2, no. 5, pp. 270-278, 2009.

[21] P. Rathee, H. Chaudhary, S. Rathee, D. Rathee, V. Kumar, and K. Kohli, "Mechanism of action of flavonoids as anti-inflammatory agents: a review," Inflammation and Allergy-Drug Targets, vol. 8, no. 3, pp. 229-235, 2009.

[22] M. I. Lefterova and M. A. Lazar, "New developments in adipogenesis," Trends in Endocrinology and Metabolism, vol. 20, no. 3, pp. 107-114, 2009.

[23] H. K. Jung, Y. S. Jeong, C.-D. Park, C.-H. Park, and J.-H. Hong, "Inhibitory effect of citrus peel extract on lipid accumulation of 3T3-L1 adipocytes," Journal of Applied Biological Chemistry, vol. 54, no. 2, pp. 169-176, 2011.

[24] T. Tsujita and T. Takaku, "Lipolysis induced by segment wall extract from Satsuma mandarin orange (Citrus unshu Mark)," Journal of Nutritional Science and Vitaminology, vol. 53, no. 6, pp. 547-551, 2007.

[25] S.-H. Bok, S.-H. Lee, Y.-B. Park et al., "Plasma and hepatic cholesterol and hepatic activities of 3-hydroxy-3- methylglutaryl-CoA reductase and acyl CoA: cholesterol transferase are lower in rats fed citrus peel extract or a mixture of citrus bioflavonoids," Journal of Nutrition, vol. 129, no. 6, pp. 1182-1185, 1999.

[26] S.-I. Kang, H.-S. Shin, H.-M. Kim et al., "Immature Citrus sunki peel extract exhibits antiobesity effects by $\beta$-oxidation and lipolysis in high-fat diet-induced obese mice," Biological and Pharmaceutical Bulletin, vol. 35, no. 2, pp. 223-230, 2012.

[27] X. Ding, S. Fan, Y. Lu et al., "Citrus ichangensis peel extract exhibits anti-metabolic disorder effects by the inhibition of PPAR $\gamma$ and LXR signaling in high-fat diet-induced C57BL/6 mouse," Evidence-Based Complementary and Alternative Medicine, vol. 2012, Article ID 678592, 10 pages, 2012.

[28] T. Kawada, T. Goto, S. Hirai et al., "Dietary regulation of nuclear receptors in obesity-related metabolic syndrome," Asia Pacific Journal of Clinical Nutrition, vol. 17, no. 1, pp. 126-130, 2008.

[29] R. M. Evans, G. D. Barish, and Y.-X. Wang, "PPARs and the complex journey to obesity," Nature Medicine, vol. 10, no. 4, pp. 355-361, 2004.

[30] R. Pakala, S.-W. Rha, P. K. Kuchulakanti, E. Cheneau, R. Baffour, and R. Waksman, "Peroxisome proliferator-activated receptor $\gamma$ : its role in atherosclerosis and restenosis," Cardiovascular Radiation Medicine, vol. 5, no. 1, pp. 44-48, 2004.

[31] M. Daval, F. Foufelle, and P. Ferré, "Functions of AMP-activated protein kinase in adipose tissue," Journal of Physiology, vol. 574, no. 1, pp. 55-62, 2006.

[32] J. Ahn, H. Lee, S. Kim, J. Park, and T. Ha, "The anti-obesity effect of quercetin is mediated by the AMPK and MAPK signaling pathways," Biochemical and Biophysical Research Communications, vol. 373, no. 4, pp. 545-549, 2008.
[33] J.-T. Hwang, I.-J. Park, J.-I. Shin et al., "Genistein, EGCG, and capsaicin inhibit adipocyte differentiation process via activating AMP-activated protein kinase," Biochemical and Biophysical Research Communications, vol. 338, no. 2, pp. 694-699, 2005.

[34] A. Woods, D. Vertommen, D. Neumann et al., "Identification of phosphorylation sites in AMP-activated protein kinase (AMPK) for upstream AMPK kinases and study of their roles by site-directed mutagenesis," The Journal of Biological Chemistry, vol. 278, no. 31, pp. 28434-28442, 2003.

[35] A. Woods, K. Dickerson, R. Heath et al., " $\mathrm{Ca}^{2+} /$ calmodulindependent protein kinase kinase- $\beta$ acts upstream of AMPactivated protein kinase in mammalian cells," Cell Metabolism, vol. 2, no. 1, pp. 21-33, 2005.

[36] S. A. Hawley, D. A. Pan, K. J. Mustard et al., "Calmodulindependent protein kinase kinase- $\beta$ is an alternative upstream kinase for AMP-activated protein kinase," Cell Metabolism, vol. 2, no. 1, pp. 9-19, 2005.

[37] X. Tong, K. A. Smith, and J. C. Pelling, "Apigenin, a chemopreventive bioflavonoid, induces AMP-activated protein kinase activation in human keratinocytes," Molecular Carcinogenesis, vol. 51, no. 3, pp. 268-279, 2012.

[38] K. Zebisch, V. Voigt, M. Wabitsch, and M. Brandsch, "Protocol for effective differentiation of 3T3-L1 cells to adipocytes," Analytical Biochemistry, vol. 425, no. 1, pp. 88-90, 2012.

[39] M. Lee, H. H. Lee, J. K. Lee, S. K. Ye, S. H. Kim, and S. H. Sung, "Anti-adipogenic activity of compounds isolated from Idesia polycarpa on 3T3-L1 cells," Bioorganic \& Medicinal Chemistry Letters, vol. 23, pp. 3170-3174, 2013.

[40] C. P. Wong, T. Kaneda, and H. Morita, "Plant natural products as an anti-lipid droplets accumulation agent," Journal of Natural Medicines, vol. 68, no. 2, pp. 253-266, 2014. 


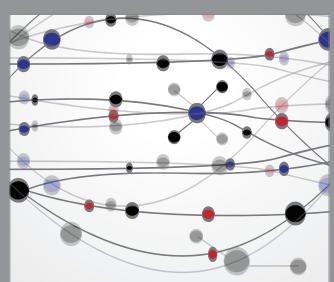

The Scientific World Journal
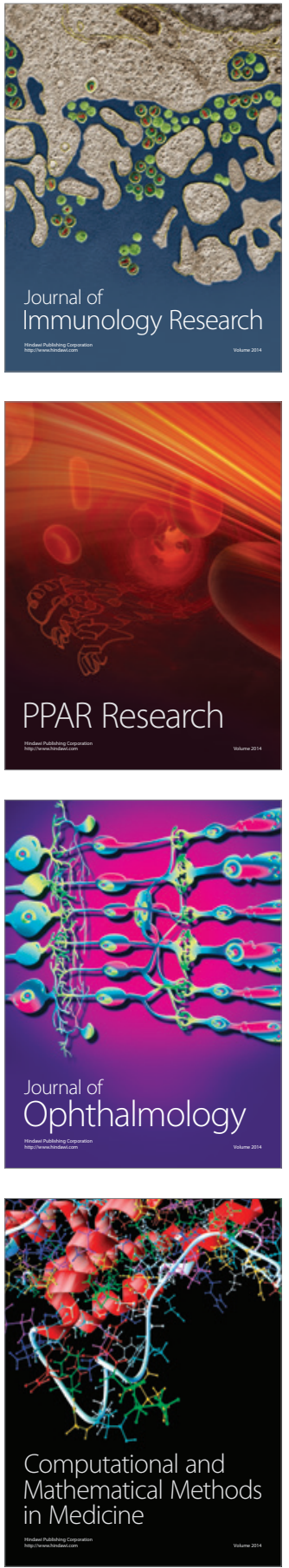

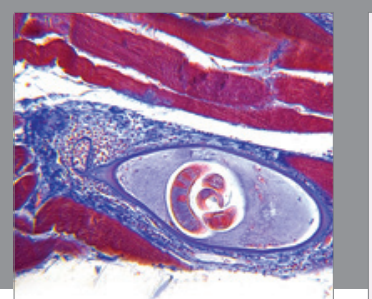

Gastroenterology Research and Practice

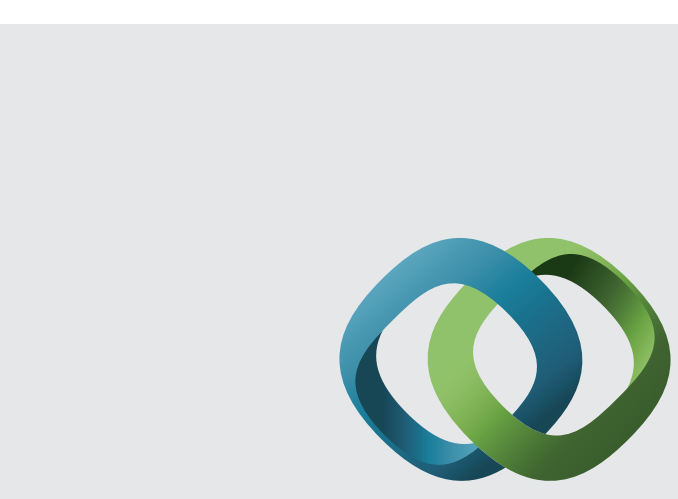

\section{Hindawi}

Submit your manuscripts at

http://www.hindawi.com
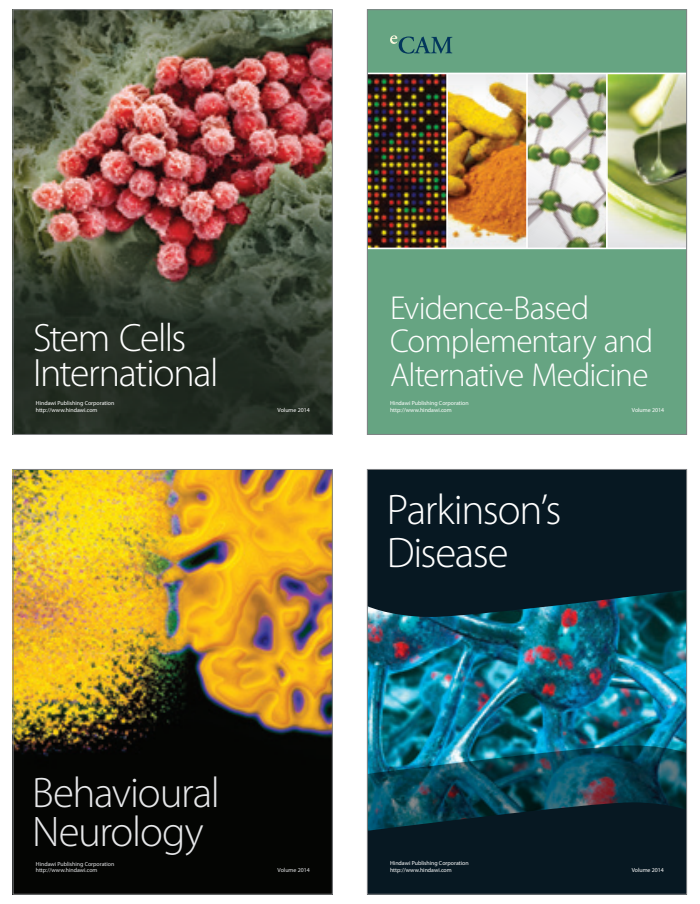
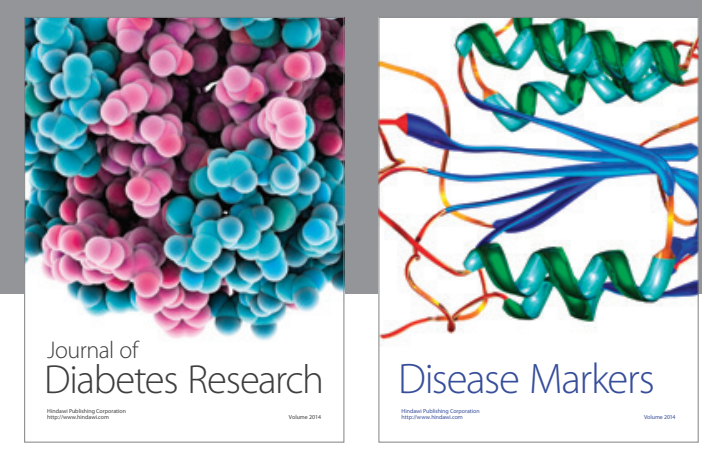

Disease Markers
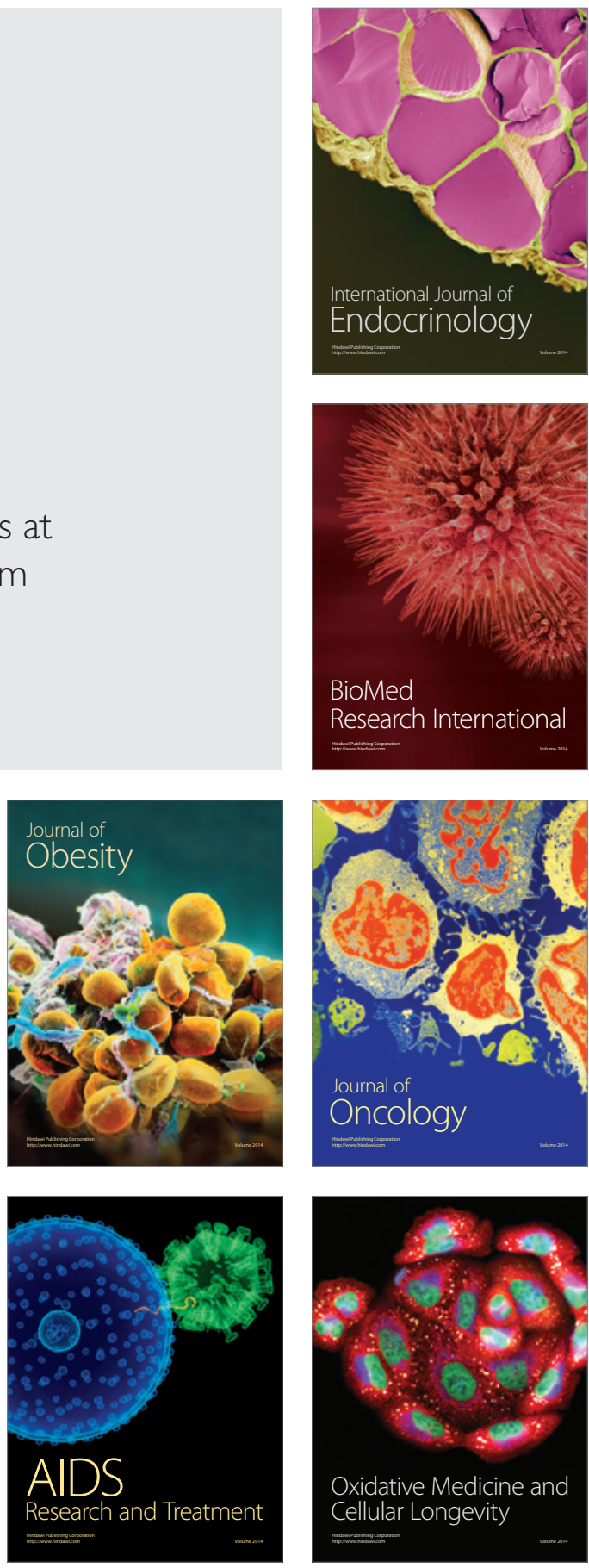